\title{
Dissociative identity disorder: validity and use in the criminal justice system $^{\dagger}$
}

\author{
Joel Paris
}

\begin{abstract}
SUMMARY
This review examines whether the diagnosis of dissociative identity disorder (DID) could be used to support a defence of 'not guilty by reason of insanity' (NGRI, or the insanity defence). The problem is that DID has doubtful validity and can easily be malingered. However, the diagnosis is listed in standard psychiatric manuals. If accepted as valid, DID would have problematic forensic implications.
\end{abstract}

\section{LEARNING OBJECTIVES}

After reading this article you will be able to:

- understand the history of the DID diagnosis

- evaluate the validity of the DID diagnosis

- appreciate, from case law, use of DID in support of an insanity defence.

\section{DECLARATION OF INTEREST}

None.

\section{KEYWORDS}

Dissociative disorders; forensic psychiatry; insanity defence; comorbidity.

\section{History of the DID diagnosis}

Janet (1924) coined the term 'dissociation', describing a state in which parts of the personality are separated into inaccessible compartments. Prince (1906) popularised the concept by writing a book describing a clinical case of multiple personalities, each of which seemed to have a separate existence. Decades later, Thigpen \& Cleckley (1954) described a very similar case, and the story was later turned into a Hollywood movie, The Three Faces of Eve. Yet while dissociative phenomena are dramatic, the diagnosis was long considered to be a rarity.

The publication of another best-selling book (also made into a movie), Sibyl (Schreiber 1973), triggered an epidemic of diagnoses of multiple personality in several countries, particularly the USA. Some claimed that these cases are surprisingly common, albeit undiagnosed, in clinical settings (Kluft 1985) and that community prevalence could be as high as 1\% (Ross 1991). Moreover, it has been claimed that the main cause of this disorder is severe childhood abuse (Putnam 1989). It should be noted that this diagnostic epidemic occurred at a time when professionals and members of the general public had serious concerns about unreported childhood abuse and its putative sequelae.

Sibylplayed an important role in popularising these ideas, both among clinicians and the general public. It was a dramatic story, with villains and a heroine. We now know that the book was an almost complete fraud (Rieber 2006). The name of the woman whom Schreiber wrote about was Shirley Ardell Mason, and Nathan (2011) has published detailed research on her life. Mason had had years of treatment but had never previously presented with dissociative symptoms. Her psychiatrist encouraged the exploration of multiple personalities and insisted that Mason must have been abused as a child. Yet Mason came from a reasonably normal family and had never been abused. Transcripts of her therapy sessions clearly show that this narrative was imposed on Mason, who may have been willing to go along with it because of her relationship with her therapist.

\section{Dissociative identity disorder and its critics}

The term 'multiple personality disorder' has been replaced by 'dissociative identity disorder' (DID) in DSM-5 (American Psychiatric Association 2013) and this is also the label used in ICD-10 (World Health Organization 1992). Between 1970 and 1979 only 39 articles on MEDLINE concerned multiple personality or DID. Between 1980 and 1989 the number of new articles cited was 212 , rising to 391 between 1990 and 1999. It has since levelled off, with 179 articles between 2000 and 2009, and 197 between 2010 and 2018.

DID has always had its critics. Many clinicians say they have never seen a case. Moreover, observers have been impressed by the sudden increase in the identification of a once-uncommon disorder, and most clinical and research reports came from a small number of centres in the USA that specialise in dissociative disorders (McHugh 2008). These settings offer extended and costly in-patient treatment
Joel Paris is Professor of Psychiatry at McGill University, Montreal, Canada. He has been a member of the Psychiatry Department at the university since 1972, serving as Department Chair from 1997 to 2007 He is currently a research associate at the Jewish General Hospital (JGH) in Montreal, and heads personality disorder clinics at both the McGill University Health Centre and JGH. He is a former Editor-in-Chief of the Canadian Journal of Psychiatry. His research interest is in borderline personality disorder.

Correspondence Professor Joel Paris, Research Associate, SMBDJewish General Hospital, 4333 Côte Ste Catherine Road, Montreal, Quebec H3T 1E4, Canada. Email: joel. paris@mcgill.ca

First received 7 Jan 2019 Final revision 22 Feb 2019 Accepted 4 Mar 2019

\section{Copyright and usage}

(c) The Royal College of Psychiatrists 2019

${ }^{\dagger}$ See commentaries, this issue. 
to reintegrate the various 'alters' into which personality has putatively fragmented (Putnam 1989). However, the diagnosis of DID often leads to a series of 'therapeutic' procedures that exaggerated the very symptoms that characterise the syndrome (Piper 2004a, 2004b).

\section{DID as an artefact of therapy}

Critics of the DID diagnosis have argued that the most parsimonious explanation for the phenomena associated with DID is that they develop in patients who are suggestible, fantasy-prone and willing to play a role, and who are treated by therapists who are convinced about the reality and ubiquity of this diagnosis (Lilienfeld 2007). Thus, the clinical picture that emerges depends on a folie à deux between therapist and patient. This is what Spanos (1996) referred to as 'role-playing', both in hypnotic states and in therapy.

This is not to deny the reality of dissociation as a symptom. Research shows that the capacity for dissociation is determined not only by the environment, but is a trait that is partially heritable (Jang 1998). This suggests that dissociative symptoms would be better understood using an interactive stress-diathesis model, in which adverse experiences amplify temperamental vulnerabilities.

But the creation of dissociative disorders by means of psychotherapy is a different phenomenon. Some patients are highly vulnerable to suggestion from therapists, and DID is most likely an artefact of specific techniques. Thus, therapists may insist that patients must have been abused during childhood. Moreover, dissociative symptoms receive strong reinforcement. This scenario creates the drama of the disorder. As a result, DID is only common in treatment settings that encourage and reward these symptoms (McHugh 2008).

\section{The malleability of memory}

The therapeutic methods developed for the evaluation and treatment of dissociative disorders are based on an incorrect theory of human memory (McNally 2003, 2012). Memories of the past are rarely factually accurate, but tell old stories in new ways, recreating and reinterpreting the past in light of the present. Few can recall childhood experiences with accuracy, and hardly anyone can remember events before the age of 3 . And it is not difficult to convince some patients that they have repressed memories of childhood abuse (Loftus 1994; Pope 1995).

Thus, the memories of patients diagnosed with DID are narratives, but need to be supported by other narratives. For example, Sibyl's therapist did not take the trouble to find out what other family members thought of her story, or whether there was any solid evidence of childhood abuse (Nathan 2011). The effects of therapist suggestion on producing false memories has been documented in the literature (Moritz 2015; Rozental 2016). This is especially the case for dissociative symptoms (Merckelbach 2017).

The use of hypnosis in treatment, and the false memories it can create, is a particularly worrying element. Hypnotic trance is, at least in some ways, a form of socially determined role-play (Spanos 1996; Lilienfeld 1999). The clinical features of DID may therefore depend on role-playing, so that patients provide memories of trauma on demand. Moreover, the number of 'alters' has a troubling tendency to increase over time, most likely due to a wish to keep therapists interested (Piper 2004a). But while most clinicians never make a DID diagnosis and do not seriously believe in it, a small group of supporters have kept the idea alive.

\section{Memory wars}

The concept of repressed and recovered memories has been challenged over and over again. One of its leading critics has been Elizabeth Loftus, whose research showed how easy it is to implant a false memory (Loftus 1994). One of the most significant critics today is Harvard's Richard McNally (2003, 2012). McNally has conducted extensive research showing that people with recovered memories score high on fantasy proneness and exhibit a tendency to develop memory illusions.

False memories are based on these mechanisms, and not on repression of trauma. The key observation is that false memories of childhood trauma are entirely unlike post-traumatic stress disorder, in which painful memories are not forgotten but return to conscious thought all too frequently. McNally's colleague Susan Clancy (2005) has shown that the same mechanisms drive false memories of alien abduction.

Unfortunately, the controversy is not over. While mainstream psychology is clear that repression and recovered memory are dubious concepts, many countries have small groups of clinicians who promote these ideas. The vast majority of DID supporters are clinicians who have never conducted any research. But they have found support from those who dissent from received opinion. For example, an article supporting the validity of recovered memory was published in the prestigious journal Psychological Bulletin (Dalenberg 2012). This publication was quickly followed by a rebuttal, written by leading experts in memory, refuting its arguments one by one (Lynn 2012). Another supporter from the mainstream linked to the dissociation and trauma movement is the British psychologist Chris Brewin (2012), who continues to insist that those 
who deny that these phenomena exist do not understand the mechanisms of human memory.

\section{Dissociative disorders in diagnostic manuals}

Early editions of the DSM (e.g. American Psychiatric Association 1968) described dissociative disorders as a subtype of 'hysterical neurosis'. But with the demise of the terms 'hysteria' and 'neurosis', these disorders became diagnostic orphans that either had to be eliminated or grouped separately. Unfortunately, the political process of preparing a new manual usually means that those who have written most about disorders outside the mainstream become considered to be experts. This is what happened when multiple personality disorder was included in DSM-III (American Psychiatric Association 1980) in a separate chapter on dissociative disorders. The diagnostic criteria were written by David Spiegel of Stanford University. He is a staunch supporter of DID (Spiegel 1994, 2011) and went on to chair the same committee for DSM-IV (American Psychiatric Association 1994) as well as DSM-5 (American Psychiatric Association 2013). Although there is little controversy about depersonalisation as a separate syndrome, DID is much more problematic.

Thus, institutional psychiatry has played an important role in legitimising DID. John Nemiah (1998), long-time editor of the American Journal of Psychiatry, was a supporter. Today the DSM, the most widely used system of classification, continues to legitimise dissociative disorders and, considering its recent revision, will do so for years to come. Those who oppose the diagnosis have to hope that the construct will eventually wither from disinterest. Yet what keeps DID alive is that the diagnosis is in the manual and has to be discussed in every textbook, with chapters written by true believers.

Although most of the interest in DID comes from the USA, the World Health Organization's classification manual ICD-10 has followed the DSM approach, and continues to do so in the latest revision (ICD-11: World Health Organization 2018).

\section{Why does DID survive as a diagnosis?}

There are several reasons for continued controversy. One is the assumption that adults who have clearly been traumatised in childhood might be disbelieved, leading to further traumatisation. Moreover, we feel great sympathy for those who have suffered trauma. Finally, the controversy has become linked to feminist issues, with doubters running the risk of being accused of not believing abused women.
Most people who have been abused in childhood suffer from painful recollections, as one sees in post-traumatic stress disorder (McNally 2012). In contrast, 'recovered memories' of childhood sexual abuse are not reliable and can be created by suggestion (Loftus 1994). Unfortunately, our sympathy for suffering allows patients claiming to have DID to become attached to a role that allows them to blame others for their problems. It may also be relevant that clinics for DID in the USA have sometimes brought in millions of dollars in fees for expensive treatments. Finally, since few physicians or clinical psychologists have ever seen a case of DID, the editors of diagnostic manuals have given decision over to those who claim to have seen hundreds of cases and who declare themselves to be experts.

The best way to understand DID is as a medical fad (Paris 2012, 2013). Fads are novel ideas that initially earn great attention and then disappear from view, a pattern that has been described as 'emerging, surging, and purging' (Best 2006). DID is only one of many fads that have afflicted psychiatry over the past century (Shorter 1997).

\section{Harmful treatment}

Another serious concern is that the treatment of DID may be counterproductive (Lilienfeld 2007). This is an issue that needs further consideration by all therapists (Rozental 2016), and one to which supporters of the DID diagnosis have not paid sufficient attention.

There have been no randomised controlled trials of therapy based on the DID diagnosis, only case reports. Lengthy and expensive treatments that are not evidence-based also tend to produce a backlash. Many critics have viewed the treatment methods used by DID enthusiasts as regressive and harmful (Piper 2004b). One review paper by a group that supports the validity of DID (Brand 2009) summarised a series of trials in which dissociative symptoms were reduced with therapy. However, all samples were small and the research designs were pre-post, not randomised controlled trials.

\section{The validity of the DID diagnosis}

Like most diagnoses in psychiatry, DID is based on clinical features, not on proven mechanisms. This is a significant problem for a disorder that could be almost entirely the result of suggestion. One of the central ideas behind DID, the repression and/or dissociation of traumatic memories, has never been accepted by memory researchers (Schachter 2008). As is well known, recollections of childhood events in adults are not necessarily reliable (McNally 2003). By and large, memories are reconfigured and reprocessed whenever recalled, and can be 
greatly modified by suggestion (Loftus 1994). But there are patients who can be convinced by therapists that childhood abuse has been forgotten and that memories of these experiences can be recovered.

\section{Psychological assessment instruments}

Another issue is whether DID can be measured using psychometric scales and semi-structured interviews. The Dissociative Experiences Scale (DES; Bernstein-Carlson 1993) is a 28-item self-report questionnaire often used in research, but its items describe common experiences, not a mental disorder with dramatic symptoms. The Structured Clinical Interview for DSM-IV Dissociative Disorders (SCID-D; Steinberg 1997) was designed to be closer to the DID construct, but there is no gold standard by which its value can be established. In short, invalid diagnostic constructs cannot be validated by measuring symptoms that are non-specific.

\section{Biological markers}

In contemporary psychiatry, many clinicians and researchers hope to support the validity of mental disorder through biological markers. The currently popular technology for measuring brain activity is functional magnetic resonance imaging (fMRI). A brain imaging study of patients with DID diagnoses conducted by Schlumpf et al (2014) reported differences in resting state at several sites in the brain that were not found in a control group. The authors claimed that their findings were inconsistent with the idea that DID is caused by suggestion. This conclusion was quite unjustified. Almost every cognitive, emotional or behavioural variation is associated with some change in the patterns one can observe on neuroimaging ( $\operatorname{Raz} 2012$ ). Reinders et al (2012) published a paper describing differences on fMRI in patients diagnosed with DID compared with a group that only simulated dissociation. But as in most imaging research, the sample was small. Moreover, one cannot assume that what one sees on fMRI is necessarily more valid than clinical observation.

\section{'Alters', 'recovered memories' and the creation of a cult}

Dissociative symptoms are seen in several mental disorders but the idea that personality can split into 'alters' that take on an independent existence is inconsistent with research in cognitive psychology (Kihlstrom 2005; Lynn 2012). These phenomena are only seen in patients who have been coached, or in defendants who have little recourse to a medical excuse for their behaviour (Lynn 2012).

Another question is whether the stories of childhood trauma told by patients with DID can be verified independently or are more likely to be fabrications. That was clearly the case with 'Sibyl'. Patihis \& Pendergrast (2019) conducted a largescale survey showing that most 'recovered memories' are responses to specific interventions by therapists who strongly believe in the concept.

This is not to say that patients with pathological dissociation do not have some kind of mental disorder (Kihlstrom 2005). But as Shorter (1994) has shown, psychopathology can take many forms, depending on cues from the social environment. As pointed out by Hacking (1995), DID is only one of several historically documented ways of expressing distress in a dramatic way. In each era, there have been patients who find a different way to do so that engages the interest of the medical profession (Shorter 1997). This is why 'hysterical' symptoms, which were more common in the 19th century, have become rare.

Unfortunately, it is possible to found a cult within the boundaries of organised medicine. That is what happened with DID. Its proponents are deeply committed to their cause and are not seriously interested in supporting claims with data. This is why mainstream psychology ignores DID and why papers on the subject have to be published in specialised journals.

The most important of these is the Journal of Trauma $\&$ Dissociation, sponsored by the International Society for the Study of Trauma and Dissociation (ISSTD), launched in 2000. The Society has also sponsored a treatment guideline for DID (International Society for the Study of Trauma and Dissociation 2011) which reflects its point of view.

\section{DID in forensic settings}

There is very little in the literature on DID in forensic settings. And what has been published fails to meet scientific standards. Conclusions depend on whether one believes that DID is a 'real' mental disorder (Brand 2017a, 2017b) or an invalid fad (Merckelbach 2018).

An edited book on this subject, first published in 2008 but recently re-released (Sachs 2018), offers 15 chapters, written by psychotherapists working in the UK, all of whom are strong believers in DID. Their approach to the subject focuses not on empirical data, but on emotion-laden appeals to 'believe the patient'. There is one chapter on criminal responsibility by a group of lawyers (Farmer 2018) that adds little to the debate.

It is difficult to find any empirical research in this area. A large textbook, with a wide range of authors taking multiple perspectives (Dell 2009), did not discuss the forensic implications of DID. Other 
reviews of the subject (Frankel 2006; Bourget 2017) fail to consider the question of the validity of DID in a way that could define the problem for the courts. By and large, the reason that DID has been rejected as an insanity defence is that abnormal states of consciousness do not correspond to a mental disorder that would meet criteria in the M'Naghten Rules, i.e. defendants did not know the nature or quality of their actions or, if they did know, they did not know that what they were doing was wrong (Farrell 2011). For example, being under the effects of substances is not generally accepted as a defence against a criminal charge.

\section{DID and the insanity defence in case law}

While rarely successful, a defence of 'not guilty by reason of insanity' (NGRI, or the so-called insanity defence) has occasionally, mostly in the USA, been invoked for defendants with DID in criminal cases (Farrell 2011). The assumption would be that, if a crime has been committed when an individual is under the influence of an 'alter', then a mental disorder has interfered with culpability. The American experience with this defence goes back several decades, but cases are now less frequent.

An early example was State v Milligan (1978). But since the defendant was a serial rapist, the decision to accept his insanity defence created a backlash and was not considered a precedent. In a murder case, State v Darnall (1980) and in a drink driving case, State $v$ Grimsley (1982), two other murder cases, State v Jones (1988) and State v Greene (1998), as well as another rape case, State $v$ Lockhart (2000), DID-based insanity defences were rejected. In the most recent case, Orndorff $v$ Commonwealth (2010), the defence was unsuccessful (Nakic 2012). Years before, Orne et al (1984) described a notorious case of a murderer who admitted to having malingered DID.

There does not appear to be any case law in the UK for DID as a basis for an insanity defence. This could reflect cultural differences between the UK and USA. (I would suggest that British professionals are less susceptible to fads.) There have been two unsuccessful insanity defences in Australia, one for a series of frauds (re Gleeson 2007) and one for a murder (re Wigginton 1990).

\section{Why DID-based insanity defences rarely work}

Dissociative states are usually related to states of mind at the time of a crime, rather than showing a chronic course such as one would expect in a severe mental disorder (Webermann 2017). No doubt the emotional state that occurs when crimes are committed can affect memory, but it is doubtful that complete amnesia can occur or that 'alters' are responsible.

Finally, dissociation is easy to fabricate, and there is a worrisome overlap between malingered symptoms and dissociative phenomena (Merckelbach 2017). Moreover, when DID has been used as an insanity defence, the accused often has no other defence. This is only one example of the thorny problems associated with assessing witness testimony in criminal cases (Radcliffe 2016).

Allowing pseudo-science into the courtroom is definitely something to avoid. Fortunately, juries have been sceptical, showing that common sense can trump the mask of 'expertise'.

\section{Conclusions}

It was only when patients who had been harmed by the methods used to treat DID started going to court that the days of the DID fad were numbered. One prominent proponent in Chicago, Bennett Braun, ended up losing his medical licence for exploiting and damaging a patient over many years of 'treatment' (Grinfeld 1999).

The decline of interest in DID also reflects a scepticism that is a backlash against faddish concepts and practices. Furthermore, we live in an era of evidence-based practice: the recommended treatment for DID has never been shown to be successful. Finally, loss of interest in DID is also linked to psychiatry's change of paradigm. Neither the theory behind the diagnosis, derived from the ideas of Janet and Freud in the late 19th century, nor the methods of treatment are consistent with the current preference for biological theories and pharmacological interventions. But as long as there is a minority who have a cultish belief in DID and repressed memories, the problem will not go away.

Unfortunately, as long as dissociative disorders comprise a separate chapter in diagnostic manuals, every textbook of psychiatry is forced to devote a chapter of its own to the subject. In my own department, there is only one person who believes in DID, but he is the one asked to teach the subject to students.

One can only hope that, with time and with attrition of its supporters, the concept of DID will be consigned to history. At that point, its false image of scientific respectability will be understood and it will not be used as a defence in criminal cases.

\section{Acknowledgement}

Pamela Radcliffe was a great help in the preparation of this manuscript.
MCO answers

$1 d \quad 2 b \quad 3 a \quad 4 b \quad 5 c$ 


\section{References}

American Psychiatric Association (1968) Diagnostic and Statistical Manual of Mental Disorders (2nd edn). APA.

American Psychiatric Association (1980) Diagnostic and Statistical Manual of Mental Disorders (3rd edn) (DSM-III). APA.

American Psychiatric Association (1994) Diagnostic and Statistical Manual of Mental Disorders (4th edn) (DSM-IV). APA.

American Psychiatric Association (2013) Diagnostic and Statistical Manual of Mental Disorders (5th edn) (DSM-5). APA.

Bernstein-Carlson E, Putnam FW (1993) An update on the Dissociative Experiences Scale. Dissociation, 6: 16-27.

Best J (2006) Flavor of the Month: Why Smart People Fall for Fads. University of California Press.

Bourget D, Gagné P, Wood SF (2017) Dissociation: defining the concept in criminal forensic psychiatry. Journal of the American Academy of Psychiatry and the Law, 45: 147-60.

Brand BL, Classen CC, McNary SW, et al (2009) A review of dissociative disorders treatment studies. Journal of Nervous and Mental Disease, 197: $646-54$.

Brand BL, Schielke HJ, Brams JS (2017a) Assisting the courts in understanding and connecting with experiences of disconnection: addressing trauma-related dissociation as a forensic psychologist, part I. Psychological Injury and Law, 10: 283-97.

Brand BL, Schielke HJ, Brams JS, et al (2017b) Assessing trauma-related dissociation in forensic contexts: addressing trauma-related dissociation as a forensic psychologist, part II. Psychological Injury and Law, 10 : 298-31.

Brewin CR (2012) A theoretical framework for understanding recovered memory experiences. In True and False Memories: Towards a Reconciliation of the Debate (Nebraska Symposium on Motivation, vol 58) (ed RF Belli): 149-74. Springer.

Clancy S (2005) Abducted: How People Come to Believe They Were Kidnapped by Aliens. Harvard University Press.

Dalenberg CJ, Brand BL, Gleaves DH, et al (2012) Evaluation of the evidence for the trauma and fantasy models of dissociation. Psychological Bulletin, 138: 550-8.

Dell PF, O'Neil JA (2009) Dissociation and the Dissociative Disorders: $D S M-V$ and Beyond. Routledge.

Farmer J, Middleton W, Devereux J (2018) Dissociative identity disorder and criminal responsibility. In Forensic Aspects of Dissociative Identity Disorder (eds A Sachs, G Galton): 79-99. Routledge.

Farrell HM (2011) Dissociative identity disorder: medicolegal challenges. Journal of the American Academy of Psychiatry and the Law, 39: 402-6.

Frankel AS, Dalenberg $C$ (2006) The forensic evaluation of dissociation and persons diagnosed with dissociative identity disorder: searching for convergence. Psychiatric Clinics North America, 29: 169-84.

Grinfeld MJ (1999) Recovered memory lawsuit sparks litigation. Psychiatric Times, 16: 12.

Hacking I (1995) Rewriting the Soul: Multiple Personality and the Sciences of Memory. Princeton University Press.

International Society for the Study of Trauma and Dissociation (2011) Guidelines for treating dissociative identity disorder in adults, third revision. Journal of Trauma and Dissociation, 12: 115-87.

Janet P (1924) Principles of Psychotherapy (trans HM Guthrie, ER Guthrie). Macmillan.

Jang K, Paris J, Zweig-Frank H, et al (1998) A twin study of dissociative experience. Journal of Nervous and Mental Disease, 186: 345-51.

Kihlstrom JF (2005) Dissociative disorders. Annual Review of Clinical Psychology, 1: 1-27.

Kluft R (1985) Childhood Antecedents of Multiple Personality Disorder. American Psychiatric Publishing

Lilienfeld SO, Lynn SJ, Kirsch I, et al (1999) Dissociative identity disorder and the sociocognitive model: recalling the lessons of the past. Psychological Bulletin, 125: 507-23.
Lilienfeld SO (2007) Psychological treatments that cause harm. Perspectives on Psychological Science, 2: 53-70.

Loftus E, Polonsky S, Fullilove M (1994) Memories of childhood sexual abuse: remembering and repressing. Psychology of Women Quarterly, 18: 67-84.

Lynn SJ, Lilienfeld SO, Merckelbach H, et al (2012) Dissociation and dissociative disorders: challenging conventional wisdom. Current Directions in Psychological Science, 21: 48-60.

McHugh PR (2008) Try to Remember: Psychiatry's Clash Over Meaning, Memory and Mind. Dana Press.

McNally RJ (2003) Remembering Trauma. Belknap Press/Harvard University Press.

McNally RJ (2012) Searching for repressed memory. In True and False Memories: Towards a Reconciliation of the Debate (ed RF Belli): 12148. Springer.

Merckelbach H, Boskovic I, Pesy D, et al (2017) Symptom overreporting and dissociative experiences: a qualitative review. Consciousness and Cognition, 49: 132-44.

Merckelbach H, Patihis L (2018) Why 'trauma-related dissociation' is a misnomer in courts: a critical analysis of Brand et al. (2017a, b). Psychological Injury and Law, 11: 370-6.

Moritz S, Fieker M, Hottenrot B, et al (2015) No pain, no gain? Adverse effects of psychotherapy in obsessive-compulsive disorder and its relationship to treatment gains. Journal of Obsessive-Compulsive and Related Disorders, 5: 51-66.

Nakic M, Thomas P (2012) Dissociative identity disorder in the courtroom. Journal of the American Academy of Psychiatry and the Law, 40: 146-8.

Nathan D (2011) Sibyl Exposed: The Extraordinary Story Behind the Famous Multiple Personality Case. Simon and Schuster.

Nemiah JC (1998) Early concepts of trauma, dissociation, and the unconscious: their history and current implications. In Trauma, Memory, and Dissociation (eds JD Bremner, CR Marmar): 1-26. American Psychiatric Association.

Orne MT, Dinges DF, Orne EC (1984) On the differential diagnosis of multiple personality in the forensic context. International Journal of Clinical and Experimental Hypnosis, 32: 118-69.

Paris J (2012) The rise and fall of dissociative identity disorder. Journal of Nervous and Mental Disease, 200: 1076-9.

Paris J (2013) Fads and Fallacies in Psychiatry. RCPsych Publications.

Patihis L, Pendergrast MH (2019) Reports of recovered memories of abuse in therapy in a large age-representative U.S. national sample: therapy type and decade comparisons. Clinical Psychological Science, 7: 3-21.

Piper A, Merskey H (2004a) The persistence of folly: a critical examination of dissociative identity disorder. Part I. The excesses of an improbable concept. Canadian Journal of Psychiatry, 49: 592-600.

Piper A, Merskey H (2004b) The persistence of folly: critical examination of dissociative identity disorder. Part II. The defence and decline of multiple personality or dissociative identity disorder. Canadian Journal of Psychiatry, 49: 678-83.

Pope HG, Hudson JI (1995) Does childhood sexual abuse cause adult psychiatric disorders? Essentials of methodology. Journal of Psychiatry \& Law, 12: 363-81.

Prince M (1906) The Dissociation of a Personality: A Biographical Study in Abnormal Psychology. Longmans, Green \& Co.

Putnam FW (1989) Diagnosis and Treatment of Multiple Personality Disorder. Guilford.

Radcliffe P (ed) (2016) Witness Testimony in Sexual Cases: Evidential, Investigative and Scientific Perspectives. Oxford University Press.

Raz A (2012) From neuroimaging to tea leaves in the bottom of a cup. In Critical Neuroscience: A Handbook of the Social and Cultural Contexts of Neuroscience (ed S Choudhury, J Slaby): 263-72. Wiley-Blackwell.

Reinders AATS, Willemsen ATM, Vos HPJ, et al (2012) Fact or factitious? A psychobiological study of authentic and simulated dissociative identity states. PLoS One, 7(6): e39279.

Rieber RWW (2006) The Bifurcation of the Self: The History and Theory of Dissociation and Its Disorders. Springer. 
Ross CA (1991) Epidemiology of multiple personality disorder and dissociation. Psychiatric Clinics of North America, 14: 503-17.

Rozental A, Kottorp A, Boettcher J, et al (2016) Negative effects of psychological treatments: An exploratory factor analysis of the Negative Effects Questionnaire for monitoring and reporting adverse and unwanted events. Plos One, 11(6): e0157503.

Sachs A, Galton G (eds) (2018) Forensic Aspects of Dissociative Identity Disorder. Routledge.

Schacter DL, (2008) Searching for Memory: The Brain, the Mind, and the Past. New York Basic Books.

Schreiber FR (1973) Sibyl. Henry Regnery.

Schlumpf YR, Reinders AA, Nijenhuis ER, et al (2014) Dissociative partdependent resting-state activity in dissociative identity disorder: a controlled FMRI perfusion study. PLoS One, 9(6): e98795.

Shorter E (1994) From the Mind into the Body: Cultural Origins of Psychosomatic Disorders. Free Press.

Shorter E (1997) A History of Psychiatry: From the Era of the Asylum to the Age of Prozac. John Wiley \& Sons.

Spanos NP (1996) Multiple Identities and False Memories: A Sociocognitive Perspective. American Psychiatric Association.

Spiegel D (ed) (1994) Dissociation: Culture, Mind and Body. American Psychiatric Publishing.

Spiegel D, Loewenstein RJ, Lewis-Fernandez R, et al (2011) Dissociative disorders in DSM-5. Depression and Anxiety, 28: 824-52.

Steinberg M, Hall P (1997) The SCID-D diagnostic interview and treatment planning in dissociative disorders. Bulletin of the Menninger Clinic, 61: $108-20$.
Thigpen CH, Cleckley H (1954) A case of multiple personality. Journal of Abnormal and Social Psychology, 49: 135-51.

Webermann AR, Brand BL (2017) Mental illness and violent behavior: the role of dissociation. Borderline Personality Disorder and Emotion Dysregulation, 4: 2-7.

World Health Organization (1992) International Statistical Classification of Diseases and related Health Problems, 10th Revision (ICD-10). WHO.

World Health Organization (2018) International Classification of Diseases, 11th revision (ICD-11). WHO (https://www.who.int/classifications/icd/en/). Accessed 8 March 2019.

\section{Cases}

Orndorff v Commonwealth (2010) 691 SE 2d 177 (Virginia).

Re: Gleeson (2007) Supreme Court of Queensland sitting as the Mental Health Court - Philippides J (Proceeding No. 0232 of 2006, judgement delivered 1st October, 2007)

Re: Wigginton (1990) Supreme Court of Queensland sitting as the Mental Health Tribunal - Ryan J (Judgment delivered 21/11/1990)

State v Darnall (1980) 161, 614 P 2d 120 (Oregon Ct App).

State v Greene (1998) 960 P.2d 980 (Washington Ct App).

State v Grimsley (1982) 444 N.E.2d 1071 (Ohio Ct App).

State v Jones (1988) 747 S.W.2d 229 (Missouri Ct App).

State v Lockhart (2000) 208 W. Va. 622 (West Virginia Ct App).

State v Milligan (1978) 77 CR 112908 (Franklin County, Ohio).

\section{MCOs}

Select the single best option for each question stem

1 The research evidence for the validity of DID is:

a relatively strong

b somewhat strong

c somewhat weak

d very weak

e untested.

\section{The use of DID for an insanity defence has} been generally:

a successful most of the time

b unsuccessful most of the time

c successful at least half of the time

d not presented to courts

e unsuccessful half of the time.

3 Human memory after trauma most often leads to:

a painful intrusive thoughts

b repression of the event

c dissociation

d symptoms of PTSD

e amnesia.
4 The case of 'Sibyl' shows that: a childhood trauma can cause DID

b psychotherapy can produce false memories

c repression of trauma can last for many years

$\mathrm{d}$ hypnosis is a valuable tool for treating dissociation

memories can be recovered intact.

5 Treatment of dissociative disorders tends:

a to be highly successful

$\mathrm{b}$ to be brief

c to increase false memories

$d$ to focus on current functioning

e to successfully recover childhood memories. 